\title{
PENGARUH TOILET TRAINING TERHADAP TINGKAT KOGNITIF ORANG TUA DAN FREKUENSI ENURESIS PADA ANAK USIA PRASEKOLAH DI PEMALANG
}

\author{
Hikmatul Janah, Livana PH, Hermanto \\ Program Studi Ilmu Keperawatan, Sekolah Tinggi Ilmu Kesehatan Kendal \\ iyma.hikmah@yahoo.com; livana.ph@gmail.com; Hermantokomting@yahoo.com
}

\begin{abstract}
ABSTRAK
Pendahuluan: Anak usia prasekolah merupakan anak yang berusia 3 sampai 6 tahun. Pada masa ini anak seharusnya sudah mampu mengendalikan fungsi kandung kemihnya sehingga tidak mengalami enuresis. Salah satu penatalaksanaan enuresis adalah menggunakan metode toilet training. Pengetahuan tentang toilet training sangat penting bagi orang tua untuk memperoleh keberhasilan anak. Tujuan penelitian ini untuk mengetahui pengaruh toilet training terhadap tingkat kognitif orang tua dan frekuensi enuresis pada anak usia prasekolah. Metode: Penelitian ini menggunakan desain quasi experiment dengan pendekatan Pretest-posttest design. Tehnik sampel menggunakan total sampling yaitu sebanyak 42 responden. Instrument yang digunakan adalah kuesioner, power point dan leaflet. Hasil: Hasil penelitian menggunakan uji paired sample t-test tentang toilet training terhadap tingkat kognitif orang tua di dapatkan nilai $\mathrm{p}$ value sebesar $0,000(\mathrm{p}<0,05)$ menunjukan ada pengaruh toilet training terhadap tingkat kognitif orang tua dan toilet training terhadap frekuensi enuresis di dapatkan hasil nilai $\mathrm{p}$ value $0,160(\mathrm{p}>0,05)$ menunjukan tidak ada pengaruh toilet training terhadap frekuensi enuresis pada anak usia prasekolah di Pemalang. Diskusi: Hasil penelitian ini di rekomendasikan kepada orang tua tentang cara mengajarkan toilet training dengan benar sejak anak berusia toodler sehingga kejadian enuresis pada anak usia prasekolah dapat berkurang.
\end{abstract}

Kata Kunci: Frekuensi enuresis, tingkat kognitif orang tua, toilet training

\begin{abstract}
Introduction: Preschool aged children are 3 to 6 years old. At this time the child should have been able to control the function of the bladder so as not to experience enuresis. One of the enuresis management is using toilet training method. Knowledge of toilet training is very important for parents to gain success. The purpose of this study was to investigate the effect of toilet training on cognitive level of parents and frequency of enuresis in preschoolers. Method: This research uses quasi experiment design with Pretest-posttest design approach. The sample technique using total sampling is 42 respondents. Instruments used are questionnaires, power points and leaflets. Result: The result of this study used paired sample t-test on toilet training on cognitive level of parent to get $p$ value of $0.000(p<0,05)$ toilet training on enuresis frequency obtained $p$ value $0,160(p>0,05)$ shows the influence of toilet training on the cognitive level of parents and there is no effect of toilet training on the frequency of enuresis in preschoolers in Pemalang. Discussion: The results of this study are recommended to parents on how to teach toilet training properly since toddler ages so that the incidence of enuresis in preschoolers can be reduced.
\end{abstract}


Keywords: Frequency of enuresis, parental cognitive level, toilet training

\section{PENDAHULUAN}

Anak usia prasekolah merupakan anak yang berusia 3 sampai 6 tahun (Wong, 2008). Pada masa ini banyak masalah kesehatan yang muncul yang sangat menentukan kualitas anak meliputi kesehatan umum, gangguan perilaku, gangguan belajar dan gangguan perkembangan (Septiarini, 2008). Salah satu gangguan kesehatan pada anak usia prasekolah yaitu enuresis atau lebih di kenal dengan ngompol. Enuresis atau mengompol adalah inkontinensia urin yang terjadi pada anak yang sudah mampu berkemih secara normal. Berdasarkan survey di Jakarta bahwa prevalensi enuresis sekitar $2,83 \%$ pada anak laki-laki dan 2,79\% pada anak perempuan. Kemudian 82,4\% mengalami enuresis noktrnal dan 17,6\% mengalami enuresis diurnal, serta 97,6\% bersifat primer dan 3,3\% sekunder (Daulay, 2008).

Mencegah gangguan mengompol dan perilaku akibat enuresis dapat diatasi dengan menggunakan metode toilet training. Hal ini mengharuskan orang tua untuk menberikan informasi yang baik dan benar tentang metode pelatihan toilet (Widyastuti, 2011). Latihan toilet training yang tidak benar atau terlalu terlambat merupakan faktor yang berkontribusi penting (Engel, 2008). Oleh karena itu, pengetahuan tentang toilet training sangat penting bagi orang tua untuk memperoleh keberhasilan pada pelaksanaan toilet training agar anak dapat menyelesaikan tugas toilet training pada usia toodler. Dengan demikian kejadian enuresis pada anak usia prasekolah dapat berkurang

Banyak orang tua kurang memahami waktu yang tepat untuk mengajarkan toilet training pada anak. Mereka beranggapan bahwa kemampuan tersebut akan dikuasai dengan sendirinya. Namun sebenarnya toilet training membutuhkan bimbingan yang intens, waktu dan kesabaran. Toilet training sudah harus diajarkan kepada anak mulai dari usia 18 bulan atau setelah anak bisa duduk. Keterlambatan toilet training akan berdampak pada kurangnya tanggung jawab pada anak, anak akan terbiasa mengabaikan kebersihan diri bahkan bisa menjadi bahan ledekan yang akhirnya akan mempengaruhi rasa percaya diri serta konsep diri anak.

Studi pendahuluan yang dilakukan peneliti dengan wawancara kepada 3 orang tua yang mempunyai anak usia prasekolah dan mengalami enuresis, mereka mengatakan anaknya masih ngompol terutama saat tidur pada malam hari. 2 orang tua mengatakan penyebab anaknya mengompol karena faktor keturunan dan 1 orang tua mengatakan penyebab anaknya mengompol karena aktifitasnya pada saat bermain seperti lari-lari. Namun berdasarkan pertanyaan terkait toilet training yang dilakukan orang tua saat anaknya masih usia toodler, 3 orang tua mengatakan belum mengajarkan toilet training dengan benar pada anak saat berusia toodler.

Adapun tujuan dari penelitian ini adalah untuk mengetahui karakteristik responden yaitu orang tua dan anak usia prasekolah, mengetahui kemampuan orang tua tentang toilet training sebelum dan sesudah dilakukan toilet training, mengidentifikasi tingkat kejadian enuresis sebelum dan sesudah toilet training serta menganalisa tingkat kognitif orang tua dan frekuensi enuresis anak usia prasekolah di RW 07 Kelurahan Wanarejan selatan Kecamatan Taman Kabupaten Pemalang.

\section{METODE}

Penelitian ini menggunakan desain quasi experiment dengan pendekatan Pretest-posttest design yang dilaksanakan di RW 07 Kelurahan Wanarejan selatan Kecamatan Taman Kabupaten Pemalang pada Februari 2017. Sampel penelitian menggunakan total sampling yaitu sebanyak 42 responden. Instrument yang digunakan adalah kuesioner, power point dan leaflet. Pengumpulan data dilakukan 
dengan metode kuesioner diambil dari penelitian Bastari (2015) tentang Hubungan toilet training terhadap kejadian enuresis pada balita umur 3-5 Tahundi PAUD Al-Khoiriyah Mranggen Polokarjo diambil dari, yang menggunakan bentuk pertanyaan tertutup (closed ended). Terdiri dari 16 pertanyaan, 14 pertanyaan menyangkut tentang toilet training dan 2 pertanyaan untuk mengetahui enuresis. Analisa data menggunakan uji paired sample t-test untuk mengetahui pengaruh toilet training terhadap tingkat kognitif orang tua dan frekuensi enuresis pada anak usia prasekolah dengan alpha 0,05 .

\section{HASIL}

Karakteristik 42 responden di RW 07 Kelurahan Wanarejan selatan Kecamatan Taman Kabupaten Pemalang terlihat pada tabel berikut:

\section{Tabel 1}

Distribusi frekuensi responden orang tua $(n=42)$.

\begin{tabular}{|c|c|c|c|}
\hline 1 & Usia & Frekuensi & $(\%)$ \\
\hline & 24-30 Tahun & 23 & 54.8 \\
\hline & 30-37 Tahun & 10 & 23.8 \\
\hline & 38-44 Tahun & 9 & 21.4 \\
\hline 2 & Jenis kelamin & & \\
\hline & Laki-laki & 0 & 0 \\
\hline & Perempuan & 100 & 100 \\
\hline 3 & Pendidikan & & \\
\hline & SD & 9 & 21,4 \\
\hline & SMP/Mts & 16 & 38,1 \\
\hline & SMA/MA & 13 & 31 \\
\hline & Perguruan tinggi & 4 & 9,5 \\
\hline 4 & Pekerjaan & & \\
\hline & Pedagang & 8 & 19,1 \\
\hline & PNS & 1 & 2,4 \\
\hline & Guru & 3 & 7,1 \\
\hline & Karyawan & 4 & 9,5 \\
\hline & Buruh & 6 & 14,3 \\
\hline & Ibu rumah tangga & 20 & 47,6 \\
\hline
\end{tabular}

Tabel 1 menunjukan bahwa dari total 42 responden, mayoritas responden orang tua berusia 24-30 tahun yaitu sebanyak 23 responden $(74 \%)$ dan semua responden berjenis kelamin perempuan (100\%), rata-rata berpendidikan SMP/MTs yaitu sebanyak 16 responden (38.1\%) serta mayoritas sebagai ibu rumah tangga yaitu sebanyak 20 responden (47.6\%).

Tabel 2

Distribusi frekuensi responden anak $(n=42)$.

\begin{tabular}{|c|c|c|c|}
\hline 1 & Umur & Frekuensi & $(\%)$ \\
\hline & 3 Tahun & 24 & 57,1 \\
\hline & 4 Tahun & 11 & 26,2 \\
\hline & 5 Tahun & 7 & 16,7 \\
\hline 2 & Jenis kelamin & & \\
\hline & Laki-laki & 24 & 57,1 \\
\hline & Perempuan & 18 & 42,9 \\
\hline 3 & Status anak & & \\
\hline & Anak kandung & 41 & 97,6 \\
\hline
\end{tabular}




Anak angkat $\quad 1 \quad 2,4$

Tabel 2 menunjukkan bahwa dari total 42 responden, mayoritas responden anak berusia 3 tahun yaitu sebanyak 24 responden $(57.1 \%)$ dan rata-rata berjenis kelamin laki-laki yaitu sebanyak 24 responden (57.1\%) serta mayoritas berstatus anak kandung yaitu sebanyak 41 responden (97.6\%).

Tabel 3

Pengaruh toilet training terhadap tingkat kognitif orang tua $(n=42)$

\begin{tabular}{lll}
\hline \multirow{2}{*}{$\begin{array}{c}\text { Tingkat } \\
\text { kognitif }\end{array}$} & \multicolumn{2}{c}{$\begin{array}{c}\text { Sebelum diberikan toilet } \\
\text { training }\end{array}$} \\
\cline { 2 - 3 } & Frekuensi & Persentase (\%) \\
\hline Rendah & 11 & 26.2 \\
Tinggi & 31 & 73.8 \\
\hline & \multicolumn{2}{l}{ Sesudah diberikan toilet training } \\
\hline Rendah & 0 & 0 \\
Tinggi & 42 & 100 \\
\hline Jumlah & 42 & 100 \\
\hline P value & 0.000 & \\
\hline
\end{tabular}

Tabel 3 menunjukan bahwa sebanyak 11 responden (26.2\%) mengalami peningkatan tingkat kognitif setelah diberikan toilet training, sehingga hasil uji statistik paired sample t-test didapatkakan nilai $\mathrm{P}$ value $=0.000 \quad(\mathrm{P}<0.05)$ maka dapat disimpulkan bahwa Ho diterima artinya ada pengaruh toilet training terhadap tingkat kognitif orang tua di RW 07 Kelurahan Wanarejan selatan Kecamatan Taman Kabupaten Pemalang.

Tabel 4

Pengaruh toilet training terhadap frekuensi enuresis anak usia prasekolah $(n=42)$

\begin{tabular}{llcl}
\hline \multirow{2}{*}{ Enuresis } & \multicolumn{2}{c}{$\begin{array}{c}\text { Sebelum diberikan } \\
\text { toilet training }\end{array}$} & \multirow{2}{*}{ Mean } \\
\cline { 2 - 3 } & Frekuensi & \multicolumn{1}{c}{$\%)$} & \\
\hline Sedikit & 17 & 40.5 & 5 \\
Banyak & 25 & 59.69 \\
& \multicolumn{4}{c}{ Sesudah diberikan } \\
& \multicolumn{2}{c}{ toilet training } \\
\hline Sedikit & 18 & 42.9 & 5.36 \\
Banyak & 24 & 57.1 & \\
\hline Total & 42 & 100 & \\
\hline P value & 0.160 & \\
\hline
\end{tabular}

Tabel 4 menunjukan bahwa 1 responden (2.4\%) mengalami penurunan jumlah frekuensi enuresis. Namun hasil uji statistik paired sample t-test didapatkan nilai $\mathrm{P}$ value $=0.160(\mathrm{P}>0.05)$ maka dapat disimpulkan bahwa Ho ditolak artinya tidak ada pengaruh toilet training terhadap frekuensi enuresis pada anak usia prasekolah di RW 07 Kelurahan Wanarejan selatan Kecamatan Taman Kabupaten Pemalang.

\section{PEMBAHASAN}

Hasil penelitian berdasarkan usia responden orang tua menunjukan responden terbanyak adalah pada usia 24-30 tahun. Banyaknya responden yang berumur 24-30 tahun berdasarkan hasil wawancara kepada orang tua bahwa setelah lulus smp atau sma responden memilih untuk menikah sehingga anak pertama berusia 3-5 tahun. Penelitian Moulhee (2012) tentang effect of the educational program upon parents' knowledge of nocturrnal enuretic children menyatakan bahwa faktor umur yang berkaitan dengan pengalaman dalam mengasuh anak dapat mempengaruhi pengetahuan ibu masalah enuresis. 
Hasil penelitian ini berbeda dengan penelitian Ningsih (2012) tentang hubungan pengetahuan ibu tentang toilet training dengan kebiasaan mengompol yang menunjukan bahwa rata-rata usia ibu adalah 33 tahun .

Usia dewasa awal adalah usia 20-40 tahun, tugas perkembangan pada masa ini adalah mulai membentuk keluarga, menjadi orang tua dan mengasuh anak serta tingkat berfikirnya sudah mulai matang. Semakin cukup usia seseorang maka maka semakin matang tingkat berfikirnya. Berdasarkan teori dan hasil penelitian lain maka dapat disimpulkan mayoritas usia responden dalam penelitian initermasuk dalam usia dewasa awal sehingga ibu dapat menerima informasi tentang toilet training dengan baik karena usia ibu yang sudah cukup matang dalam berfikir.

Hasil penelitian berdasarkan jenis kelamin orang tua menunjukan bahwa semua responden berjenis kelamin perempuan. Hasil penelitian ini sejalan dengan penelitian Widyastuti (2011) tentang pengaruh penyuluhan toilet training pada orang tua terhadap kejadian enuresis, yang menyatakan bahwa mayoritas jenis kelamin orang tua adalah perempuan yaitu $60 \%$. Hal ini sesuai dengan teori Hidayat (2006) yang menyatakan bahwa ibu sangat berperan penting dalam proses tumbuh kembang anak terutama dalam hal toilet training. Jadi berdasarkan teori dan penelitian lain maka dapat disimpulkan bahwa ibu adalah orang yang paling dekat dengan anak sehingga semua responden dalam penelitian ini adalah berjenis kelamin perempuan.

Hasil penelitian berdasarkan pendidikan menunjukan mayoritas responden orang tua adalah berpendidikan SMP. Penelitian ini sejalan dengan penelitian Musfiroh (2014) tentang penyuluhan terhadap sikap ibu dalam memberikan toilet training pada anak. Hasil penelitian ini berbeda dengan penelitian Hidayat (2010) tentang gambaran pengetahuan ibu tentang toilet training bahwa paling banyak pendidikan ibu adalah sarjana $(55,2 \%)$.

Perbedaan hasil penelitian dapat terjadi karena tempat penelitian yang berbeda. Tempat penelitian dalam penelitian ini dilakukan di lingkungan yang padat penduduk, Pendidikan sangat penting bagi orang tua karena dapat mempengaruhi pengetahuanya tentang masalah kesehatan. Hal ini sesuai dengan teori Wawan (2010) yang menyatakan bahwa tingkat pendidikan dapat mempengaruhi pengetahuan seseorang tentang kesehatan. Pengetahuan orang tua tentang toilet training dapat mempengaruhi keberhasilan anak dalam menyelesaikan tugas toilet training pada usia toodler sehingga pada usia prasekolah anak sudah tidak mengalami enuresis. Jadi berdasarkan teori dan penelitian-penelitian lain maka dapat disimpulkan bahwa pendidikan orang tua dalam setiap lingkungan berbeda-beda dan pendidikan orang tua sangat penting karena dapat mempengaruhi tumbuh kembang anak.

Hasil penelitian berdasarkan pekerjaan menunjukan mayoritas responden adalah ibu rumah tangga. Hasil penelitian ini sejalan dengan beberapa penelitian yang dilakukan oleh Hidayat (2010) tentang gambaran pengetahuan ibu tentang toilet training yang menyatakan bahwa ibu yang mempunyai anak usia prasekolah mayoritas adalah sebagai ibu rumah tangga. Hasil penelitian ini berbeda dengan penelitian Adawiyah (2016) tentang hubungan kesiapan psikologis dengan kesiapan enuresis pada anak yang menyatakan bahwa mayoritas pekerjaan orang tua adalah petani.

Mayoritas pekerjaan dalam penelitian ini adalah ibu rumah tangga. Ibu yang tidak bekerja memiliki waktu luang yang cukup banyak serta dapat membesarkan anak dan berkumpul dengan orang banyak sehingga dapat berbagi pengalaman dalam membesarkan anak dan semakin banyak informasi yang didapat. Jadi berdasarkan hasil penelitian lain maka dapat disimpulkan bahwa pekerjaan orang tua dalam setiap lingkungan berbeda-beda, namun dengan mayoritas pekerjaan orang tua sebagai ibu 
rumah tangga diharapkan ibu lebih baik dalam merawat anak terutama dalam masalah kesehatan terkait toilet training.

Hasil penelitian berdasarkan usia anak prasekolah yang mengalami enuresis menunjukan mayoritas responden adalah berusia 3 tahun. Penelitian ini berbeda dengan penelitian Salvianto (2013) tentang pengaruh pendidikan kesehatan bladder retention training terhadap kejadian enuresis pada anak usia prasekolah yang menyatakan bahwa kejadian enuresis pada anak usia prasekolah sebanyak $54 \%$ didominasi umur 5 tahun.

Hasil penelitian yang berbeda juga yaitu dalam penelitian Ningsih (2012) tentang hubungan pengetahuan ibu dan perilaku ibu dalam menerapkan toilet training dengan kebiasaan mengompol yaitu rata-ratausia anak prasekolah yang masih mengompol adalah berusia 4 tahun. Perbedaan usia terhadap kejadian enuresis bisa disebabkan karena beberapa faktor, salah satunya dapat disebabkan karena tempat penelitian yang berbeda serta kegagalan orang tua dalam mengajarkan toilet training kepada anak.

Toilet training seharusnya sudah diajarkan kepada anak sejak usia toodler. Hal ini sesuai dengan teori Hidayat (2006) yang menyatakan bahwa toilet training sudah harus diajarkan kepada anak mulai dari usia 18 bulan atau setelah anak bisa duduk, sehingga akan membuat semakin matangnya persiapan psikologis pada anak dan akhirnya anak akan mampu melakukan buang air kecil dan besar dengan baik, dan pada usia prasekolah anak sudah tidak lagi mengalami enuresis. Berdasarkan teori dan penelitian-penelitian lain maka dapat disimpulkan bahwa enuresis dapat terjadi pada anak usia prasekolah (3-5 tahun) yang dapat disebabkan karena kegagalan orang tua dalam mengajarkan toilet training kepada anak.

Hasil penelitian berdasarkan jenis kelamin anak prasekolah yang mengalami enuresis menunjukan mayoritas responden adalah berjenis kelamin laki-laki. Penelitian ini sejalan dengan penelitian Ningsih (2012) tentang hubungan pengetahuan ibu dan perilaku ibu dalam menerapkan toilet training dengan kebiasaan mengompol, yang menyatakan bahwa prevalensi enuresis pada anak usia prasekolah mayoritas adalah berjenis kelamin laki-laki yaitu sebanyak 53.7\%. Hasil penelitian ini berbeda dengan penelitian Salvianto (2013) tentang pengaruh pendidikan kesehatan bladder retention training terhadap kejadian enuresis pada anak usia prasekolah yang menyatakan bahwa sebagian besar jenis kelamin anak yang mengalami enuresis adalah perempuan yaitu $64 \%$.

Perbedaan hasil penelitian dapat disebabkan karena kapasitas kandung kemih pada setiap anak berbeda. Sesuai dengan teori Wong (2008) yang menyatakan bahwa pada anak usia prasekolah perkembangan system organ kandung kemih pada setiap anak mempunyai kapasitas kandung kemih yang berbeda, namun pada umunya anak perempuan memiliki kapasitas yang lebih besar dibandingkan dengan anak laki-laki. Jadi berdasarkan teori dan penelitian-penelitian lain maka dapat disimpulkan bahwa kapasitas kandung kemih yang berbeda pada setiap anak dapat menyebabkan kejadian enuresis baik pada perempuan maupun laki-laki. Namun dalam penelitian ini mayoritas responden yang mengalami enuresis berjenis kelamin laki-laki. Hal ini disebabkan karena kapasitas kandung kemih pada laki-laki lebih kecil dibandingkan perempuan.

Hasil penelitian berdasarkan status anak menunjukan mayoritas responden berstatus anak kandung dan hanya 1 responden yang merupakan anak angkat. Memiliki anak angkat tidak seperti memiliki anak kandung sendiri. Beberapa orang merasa sulit mendidik anak angkat karena biologisnya berbeda dimana anak angkat akan lebih banyak seperti orang tua kandungnya. Dalam hal ini mungkin penyebab anak angkat mengalami enuresis selain tingkat kognitif orang tua tentang toilet training adalah faktor keturunan. Sesuai dengan teori Kurniawati (2007) yang menyatakan bahwa apabila 
kedua orang tua mempunyai riwayat enuresis maka $77 \%$ anak kemungkinan mengalami enuresis, namun apabila hanya salah satu orang tua yang mempunyai riwayat enuresis maka $44 \%$ anak kemungkinan mengalami enuresis, sedangkan apabila kedua orang tua tidak mengalami enuresis maka $15 \%$ anak kemungkinan mengalami enuresis. Berdasarkan uraian diatas maka dapat disimpulkananak kandung dapat mengalami enuresis karena faktor keturunan dan apabila anak angkat mengalami enuresis kemungkinan disebabkan karena orang tua kandungnya mengalami riwayat enuresis.

\section{Pengaruh toilet training terhadap tingkat kognitif orang tua}

Hasil penelitian menujukan setelah diberikan toilet training sebanyak 24 responden mempunyai tingkat kognitif yang lebih tinggi dari sebelum diberikan toilet training. Hasil uji statistik didapatkan nilai sig 0.000 . Karena nilai sig $<0.05$ maka dapat disimpulkan bahwa Ho diterima artinya ada pengaruh toilet training terhadap tingkat kognitif orang tua di RW 07 Kelurahan Wanarejan selatan Kecamatan Taman Kabupaten Pemalang.

Hasil penelitian ini sejalan dengan penelitian Probowati (2014) tentang pengaruh pendidikan kesehatan tentang toilet training anak usia 1-3 tahun terhadap pengetahuan ibu,yang menunjukan hasil nilai probabilitas yaitu $0.000(<0.05)$ yang artinya Ho diterima maka pengaruh pendidikan kesehatan tentang toilet training anak usia 1-3 tahun terhadap pengetahuan ibu. Terjadinya peningkatan tingkat kognitif tentang toilet training pada responden disebabkan karena responden telah menerima informasi terkait toilet training yang didapatkan pada saat penyuluh memberikan pendidikan kesehatan tentang toilet training kepada responden. Hal ini sesuai dengan teori Machfoed (2009) yang menyatakan bahwa pendidikan kesehatan merupakan proses perubahan dengan tujuan untuk mengubah individu, kelompok atau masyarakat menuju hal-hal positif secara terencana. Perubahan tersebut meliputi pengetahuan, sikap dan ketrampilan yang dilakukan melalui proses pendidikan kesehatan.

Adanya pengaruh toilet training terhadap tingkat kognitif orang tua dapat memberikan dampak positif. Anak yang mengalami enuresis selain disebabkan karena faktor keturunan, salah satunya bisa disebabkan karena kegagalan toilet training pada saat anak masih berusia toodler. Hal ini didukung dengan teori Aziz (2006) yang menyatakan bahwa kegagalan dalam toilet training dapat menyebabkan terjadinya enuresis.

Kegagalan toilet training dapat disebabkan karena kurangnya pengetahuan orang tua tentang toilet training. Jadi dengan adanya peningkatan tingkat kognitif orang tua tentang toilet training maka anak yang mengalami enuresis dapat menyelesaikan tugas toilet training sehingga anak tidak mengalami enuresis. Berdasarkan uraian diatas maka dapat disimpulkan pendidikan kesehatan tentang toilet training dapat memberikan pengaruh terhadap tingkat kognitif orang tua tentang toilet training, sehingga diharapkan dapat memberikan dampak positif salah satunya yaitu anak tidak lagi mengalami enuresis.

\section{Pengaruh toilet training terhadap frekuensi enuresis pada anak usia prasekolah}

Hasil penelitian menujukan setelah diberikan toilet training beberapa responden mengalami penurunan dan penaikan jumlah frekuensi enuresis dari sebelum diberikan toilet training. Hasil uji statistik didapatkan bahwa nilai t hitung adalah 1.432 dengan sig 0.160 . Karena nilai sig $>0.05$ maka dapat disimpulkan bahwa Ho ditolak artinya tidak ada pengaruh toilet training terhadap frekuensi enuresis di RW 07 Kelurahan Wanarejan selatan Kecamatan Taman Kabupaten Pemalang. Hasil penelitian ini berbeda dengan penelitian Widyastuti (2011) tentang pengaruh penyuluhan toilet training pada orang tua terhadap kejadian enuresis yang menunjukan nilai $0.002(\mathrm{P}<0.05)$ sehingga Ha diterima dan Ho ditolak yang artinya ada pengaruh penyuluhan toilet training pada orang tua terhadap kejadian enuresis. 
Pemberian pendidikan kesehatan tentang toilet training pada orang tua seharusnya dapat mempengaruhi frekuensi enuresis pada anak usia prasekolah. Karena pada penelitian ini hanya sedikit responden yang mengalami penurunan jumlah frekuensi enuresis, sehingga setelah diuji statistik memperoleh hasil bahwa toilet training belum bisa dikatakan dapat mempengaruhi frekuensi enuresis. Hal ini dapat disebabkan karena faktor sosial budaya masyarakat yang kurang baik, seperti halnya mayoritas pendidikan masyarakat adalah SMP sehingga dapat menyebabkan kurangnya pengetahuan masyarakat tentang kesehatan. Selain itu keterbatasan waktu penelitian yang hanya 6 minggu yaitu pre 14 hari dan post 28 hari, sedangkan keberhasilan toilet training membutuhkan bimbingan yang intens, waktu dan kesabaran.

Penelitian ini juga dilakukan pada musim hujan sehingga dapat mempengaruhi frekuensi urin yang keluar menjadi lebih banyak. Sesuai teori Bararah (2009) yang menyatakan bahwa hujan yang terus menerus atau menggunakan pendingin udara yang berlebihan menyebabkan udara dingin sehingga lebih sering ke kamar mandi. Dalam lingkungan yang dingin tubuh manusia cenderung untuk tidak mengeluarkan keringat sehingga cairan akan keluar lebih banyak melalui urin.

Faktor keturunan merupakan penyebab dari enuresis primer. Hal ini sesuai dengan teori Kurniawati (2007) yang menyatakan bahwa apabila kedua orang tua mempunyai riwayat enuresis maka $77 \%$ anak kemungkinan mengalami enuresis, namun apabila hanya salah satu orang tua yang mempunyai riwayat enuresis maka $44 \%$ anak kemungkinan mengalami enuresis, sedangkan apabila kedua orang tua tidak mengalami enuresis maka $15 \%$ anak kemungkinan mengalami enuresis. Berdasarkan teori dan penelitian lain maka dapat disimpulkan bahwa tidak adanya pengaruh toilet training terhadap frekuensi enuresis di RW 07 Kelurahan Wanarejan selatan Kecamatan Taman Kabupaten Pemalang, disebabkan karena perubahan yang masih sedikit sehingga masih dalam kategori banyak. Selain itu dapat disebabkan karena faktor keturunan serta penelitian yang dilakukan pada musim hujan.

\section{SIMPULAN DAN SARAN \\ Simpulan}

Hasil penelitian ini menunjukkan bahwa terdapat pengaruh toilet training terhadap tingkat kognitif orang tua dan tidak ada pengaruh toilet training terhadap frekuensi enuresis pada anak usia prasekolah di RW 07 Kelurahan Wanarejan Selatan Kecamatan Taman Kabupaten Pemalang.

\section{Saran}

Perlu dilakukan penelitian lebih lanjut tidak hanya pengaruh toilet training terhadap tingkat kognitif orang tua dan frekuensi enuresis pada anak usia prasekolah serta mencari referensi yang lebih banyak sehingga dapat memadukan antara teori dan hasil penelitian yang diperoleh di lapangan.

\section{DAFTAR PUSTAKA}

Adawiyah, R., \& Adiguna, L. A. (2016). Hubungan Kesiapan Psikologis Dengan Enuresis Pada Anak. Jurnal Sangkareang Mataram. ISSN No 2355-9292.

Aziz, R. U. (2006). Jangan Biarkan Anak Kita Tumbuh Dengan Kebiasaan Buruk. Solo: Tiga Serangkai.

Bararah, V. F. (2009). Penyebab Sering Pipis Saat Cuaca Dingin (internet). Tersedia dalam : http://m.detik.com (diakses 02 Maret 2017).

Bastari, A. (2015). Hubungan Toilet Training Terhadap Kejadian Enuresis Pada Balita Umur 3-5 TahunDi PAUD Al-Khoiriyah Mranggen Polokarjo. Skripsi Publikasi.Ungaran : Ngudi Waluyo.

Daulay, R. S. (2008). Enuresis. Medan : Fakultas Kedokteran Universitas Sumatra Utara. 
Engel, J. (2008). Pengkajian Pediatrik : Seri Pedoman Praktis. Jakarta : EGC.

Hidayat, A. A. (2006). Pengantar Ilmu Keperawatan Anak. Jakarta: Salemba Medika.

Hidayat, I. H. (2010). Gambaran Pengetahuan Ibu Tentang Toilet Training Pada Anak Usia Sekolah/TK di TK Al-Azhar.Skripsi Publikasi.Medan : Fakultas Kedokteran Universitas Sumatra Utara.

Kurniawati, F. (2008). Enuresis. Buletin Penelitian RSU Dr. Soetomo. 89-85.

Macfoed. (2009). Promosi Kesehatan. Jakarta.EGC.

Moulhee, Najeeb, M. S. (2012). Effect of the Educational Program upon Parents' Knowledge of Nocturrnal Enuretic Children. World Journal of Medical Sciences 7 (3), 137-146. ISSN 18173055 .

Musfiroh, M., \& Wisudaningtyas, B., L. (2014). Penyuluhan Terhadap Sikap Ibu Dalam Memberikan Toilet Training Pada Anak. Jurnal Kesehatan Masyarakat, 9 (2), 157166.Http://Journal.unnes.ac.id/nju/index.php/kemas.

Ningsih, S. (2012). Hubungan Pengetahuan dan Perilaku Ibu Dalam Menerapkan ToiletTraining Dengan Kebiasaan Mengompol Pada Anak Usia Prasekolah di Rw 2 Kelurahan Babakan Kota Tangerang. Jakarta : UIN Syarif Hidayatullah.

Probowati, R. W., \& Arifah, S. (2014). Pengaruh Pendidikan Kesehatan TentangToilet Training Anak Usia 1-3 Tahun Terhadap Pengetahuan Ibu Di Desa Sambon Banyudono Boyolali. Skripsi. FIK. Universitas Muhammadiyah Surakarta.

Salvianto, Y. (2013). Pengaruh pendidikan kesehatan Bladder Retention Training Terhadap Kejadian Enuresis Pada Anak Usia Prasekolah di Surakarta.Skripsi Publikasi. Surakarta : UMS.

Septiarini, C. (2008). Pengembangan Metode dan Media Diari Makanan. Skripsi Publikasi. Jakarta : FKM UI.

Wawan, A \& Dewi, M. (2010). Teori dan Pengukuran Pengetahuan, Sikap dan Perilaku. Yogyakarta: Nuha Medika.

Widyastuti, K., \& Hendarsih, S. (2011). Pengaruh Penyuluhan Toilet Training Pada Orang Tua TerhadapKejadian Enuresis di Taman Kanak-kanak Bhakti Siwi Kalimeneng Kemiri Purworejo.Naskah Publikasi. STIKES Aisyiyah, Yogyakarta.

Wong, D.L. (2008). Buku Ajar Keperawatan Pediatrik. Jakarta : EGC. 